\title{
Guía de Práctica Clínica: Recomendaciones sobre profilaxis y tratamiento de la Influenza tipo A (H1N1) en embarazadas
}

Clinical Practice Guideline: Recommendations for profilaxis and treatment of Influenza A (H1N1) in pregnant women

Resumido de: Grupo Promotor de Políticas Informadas (GPPI). Instituto de Investigaciones Epidemiológicas. Academia Nacional de Medicina. Ministerio de Salud de la Nación. Influenza tipo A (H1N1) en embarazadas: Síntesis de la evidencia y recomendaciones sobre profilaxis y tratamiento; 2009.

\section{Introducción}

En abril del 2009 se identificó el primer caso de infección humana por virus de influenza tipo A ( $\mathrm{H} 1 \mathrm{~N} 1)$ transmitido de persona a persona. En Argentina, la confirmación oficial del primer caso se realizó el 8 de mayo del 2009. Al 14 de julio del 2009 , se habían reportaron 3056 casos confirmados y 137 fallecidos, con un pico de incidencia en niños, adolescentes y adultos jóvenes. De los casos confirmados en mujeres, 415 $(32 \%)$ ocurrieron en edad reproductiva, dato importante ya que las embarazadas tendrían un riesgo mayor de presentar complicaciones y morir por esta enfermedad. Hasta Julio del 2009, se habrían reportado 23 muertes en embarazadas en todo el país, pero se estima un subregistro elevado. Teniendo en cuenta el mayor riesgo de las embarazadas y la existencia de distintas recomendaciones de tratamiento y quimioprofilaxis, se decidió realizar una revisión exhaustiva de la evidencia nacional e internacional sobre el uso de antivirales en esta población.

\section{Búsqueda y selección de la evidencia}

Búsqueda manual en organismos internacionales, sitios oficiales de los Ministerios de Salud de Europa y América, Ministerio de Salud de la Nación, todos los Ministerios de Salud provinciales y sociedades científicas. Se realizó además una búsqueda electrónica en MEDLINE, en la Biblioteca Virtual de Salud y en el Centro de Revisiones y Diseminación, en Excelencia Clínica, Tripdatabase y Pubgle. Se utilizaron como palabras clave "Influenza A Virus, H1N1 Subtype"; "Zanamivir"; "Oseltamivir" y "pregnancy".

Se incluyeron todos aquellos documentos que cumplieron con al menos uno de los siguientes criterios: incluír una o más recomendaciones sobre uso de antivirales para prevención o tratamiento de embarazadas por Influenza H1N1 pandémica, contener evidencia sobre la farmacocinética y potenciales eventos adversos asociados al uso de oseltamivir o zanamivir en embarazadas o describir la evolución del virus de la influenza en esta población. 56 artículos cumplieron los criterios de inclusión y fueron los utilizados para el análisis y síntesis de la evidencia.

\section{¿Cuál es el riesgo de la influenza A para las embarazadas?}

Las embarazadas constituyen un grupo de riesgo para presentar complicaciones graves e incluso la muerte por influenza, en particular durante el segundo y tercer trimestre, de acuerdo a las observaciones en los períodos pandémicos e interpandémicos. La influenza en embarazadas en las pandemias de 1918 y 1957 se asoció con una elevada frecuencia de neumonía (50\% de las embarazadas infectadas) de mortalidad materna $(50 \%)$ y de interrupción temprana del embarazo (50\%).

En la epidemia actual se reportó un número significativo de casos en embarazadas afectadas por el virus H1N1 en Estados Unidos, algunas de las cuales evolucionaron con complicaciones graves e incluso, la muerte. En Argentina, aún no se conoce el número de embarazadas afectadas por el nuevo virus, pero se estima que es elevado al igual que el número de muertes relacionadas con las complicaciones de esta enfermedad.

\section{¿Cuál es el riesgo de la influenza A para el feto?}

La evidencia sobre los efectos del virus de la influenza en el feto es menos consistente. Algunos estudios encontraron una asociación de la infección de influenza durante el embarazo con la aparición de anomalías congénitas, aunque se considera que esta relación podría estar también vinculada a la hipertermia. Por otro lado, es difícil diferenciar los efectos teratogénicos de la causa de la fiebre y de la fiebre en sí misma; sin embargo, es conveniente tratar la fiebre en toda mujer embarazada teniendo en cuenta el riesgo que la hipertermia parece tener sobre el feto. El paracetamol es la droga de elección.

¿Cuál es la evidencia sobre la seguridad del uso de antivirales en el embarazo?

Existe escasa evidencia sobre la seguridad del uso de oseltamivir y zanamivir en embarazadas. Según la FDA (Food and Drugs Administration - Estados Unidos) se trata de medicamentos categoría $C$, lo que significa que no se han realizado estudios clínicos para evaluar su inocuidad en esta población. La evidencia sobre la seguridad proviene de estudios de laboratorio y/o en animales así como de resultados de la vigilancia post comercialización. Los estudios en animales, en placenta humana ex vivo así como la revisión de los casos de embarazadas expuestas al oseltamivir durante el embarazo (en particular, en el primer trimestre) realizada a partir de la vigilancia post-comercialización, indicarían que el riesgo de anomalías congénitas no es mayor al observado en la población general. La evidencia sobre la seguridad del uso del zanamivir en embarazadas es aún más escasa y proviene de opiniones de expertos, que consideran que su potencial riesgo teratogénico sería bajo dada su reducida biodisponibilidad y pasaje a sangre.

¿Cuáles son las recomendaciones internacionales y nacionales en relación al tratamiento de las embarazadas sospechosas de infección por influenza pandémica?

Existe consenso para la indicación de tratamiento a las embarazadas durante la pandemia en curso, dado que los beneficios del tratamiento y los riesgos de no tratar son mayores que el potencial riesgo teratogénico del antiviral.

A favor de esta recomendación se publicaron dos revisiones de la evidencia disponible sobre la seguridad del uso de oseltamivir en embarazadas. Las recomendaciones acerca del tipo de droga a utilizar varían de acuerdo al organismo que efectúa la recomendación: algunos recomiendan zanamivir (5mg inhalados, dos veces por día, por cinco días) por su baja biodisponibilidad y por ende, su menor riesgo teratogénico potencial. Otros recomiendan oseltamivir $(75 \mathrm{mg}$ vía oral, dos veces por día, por cinco días) ya que consideran que es una droga segura y que actúa sistémicamente para controlar la infección.

Una posición intermedia, recomienda zanamivir para formas leves en el primer trimestre (riesgo más alto de que ocurra efecto teratogénico y evidencia que muestra que el mayor riesgo de complicaciones de influenza se observa principalmente en el segundo y tercer trimestre) y oseltamivir para formas moderadas a graves y/o para tratamiento de la infección en el segundo y tercer trimestre.

Para resumir, todas las recomendaciones nacionales avalan el uso de medicación antiviral en las embarazadas infectadas por 
influenza pandémica, siendo el oseltamivir el fármaco de primera elección; siendo la única excepción el Ministerio de Salud de la Provincia de Buenos Aires, que recomienda en forma indistinta el oseltamivir o el zanamivir.

¿Cuáles son las recomendaciones internacionales y nacionales en relación a la profilaxis de las embarazadas en contacto estrecho con un caso sospechoso o confirmado de Influenza tipo A (H1N1) pandémica?

Se identificaron diez documentos que contienen recomendaciones sobre profilaxis en embarazadas. Todos, a excepción del elaborado por el Instituto Mexicano de Seguridad Social, recomiendan el uso de profilaxis en las embarazadas que han tenido contacto estrecho con un caso confirmado o probable de influenza $\mathrm{A}(\mathrm{H} 1 \mathrm{~N} 1)$ pandémica.

Se recomiendan tanto el oseltamivir (75 mg vía oral, una vez por día, diez días) como el zanamivir (5mg inhalados, una vez por día, por diez días) a las embarazadas cursando el segundo o tercer trimestre. Dejan a criterio del médico la indicación en el primer trimestre y puerperio inmediato (SAI-SAP). Se menciona que el zanamivir podría preferirse debido a su menor biodisponibilidad.

Palabras claves: embarazo, tratamiento, gripe pandèmica, gripe H1N1. Keywords: pregancy, therapy, pandemic influenza, H1N1 influeza.

Fuentes de financiamiento: Fondos pertenecientes al PROYECTO FESP, Comisión Nacional Salud Investiga, Ministerio de Salud de la Nación.

\section{Comentario}

Como es habitual en estas latitudes, la pandemia del virus de influenza $\mathrm{A}(\mathrm{H} 1 \mathrm{~N} 1)$ nos tomó por sorpresa en un momento en que el sobrecargado sistema de salud argentino trataba de controlar la epidemia de Dengue.

A los ominosos pronósticos iniciales de los organismos internacionales de salud, y al cuestionable manejo mediático de la información, con la generación dirigida de pánico social, se sucedieron los reportes basados en datos objetivos, que lamentablemente dejaron de actualizarse demasiado pronto a nivel nacional, cuando el virus se extendió a todo el país.

Lo que sí sabemos es que se trata de una nueva mutación viral, que ataca principalmente a gente joven y sana, con una virulencia menor a la temida inicialmente, sin por ello dejar de ser importante en personas predispuestas, como embarazadas y puérperas, que se encuentran en un estado de inmunodepresión transitoria, con un mayor riesgo de sufrir complicaciones graves debido a la influenza $\mathrm{A}(\mathrm{H} 1 \mathrm{~N} 1)$
En este contexto, existe consenso sobre la mayor probabilidad de beneficios que de riesgos con el tratamiento o la quimioprofilaxis con zanamivir u oseltamivir en embarazadas ${ }^{12}$.

Debido a su efecto general, se prefiere el tratamiento con oseltamivir. Sin embargo, es menos claro qué medicamento es mejor para la profilaxis. Si bien se puede preferir el zanamivir por su limitada absorción general, se debe considerar la posibilidad de que ocurran complicaciones respiratorias asociadas a su uso debido a que la ruta de administración es inhalada, especialmente en mujeres que tienen riesgo de sufrir problemas respiratorios.

\section{Conclusiones de la comentadora}

La mayoría de las recomendaciones favorece el uso de oseltamivir o zanamivir en la profilaxis y tratamiento de la gripe pandémica en embarazadas.

Victoria Wurcel [ Servicio de Medicina Familiar y Comunitaria del Hospital Italiano de Buenos Aires y Dirección de Calidad en Servicios de Salud del Ministerio de Salud y Ambiente, Argentina ] victoria.wurcel@ hospitalitaliano.org.ar

Resumido por Wurcel V. Guía de práctica clínica: Recomendaciones sobre profilaxis y tratamiento de la Influenza tipo A (H1N1) en embarazadas .Evid. actual. práct. Ambul;;12(3), 112-113 - Jul-Sep 2009. Resumido de: Grupo Promotor de Politicas Informadas (GPPI). Instituto de Investigaciones Epidemiológicas. Academia Nacional de Medicina. Ministerio de Salud de la Nación. Influenza tipo A (H1N1) en embarazadas: Síntesis de la evidencia y recomendaciones sobre profilaxis y tratamiento;2009.

Disponible en URL: www.saludinvestiga.org.ar/biblioteca/iecs-academia/pandemia_embarazadas_msal.pdf

\section{Referencia}

1. Center for disease control. Información para los médicos sobre la influenza porcina y las embarazadas. Disponible en: www.cdc.gov/h1n1flu/espanol/medicos-sobre-mujeresembarazadas.htm

2. Center for disease control. Información sobre la influenza porcina en cerdos y personas. Disponible en:www.cdc.gov/h1n1flu/espanol/influenza-porcina-en-los-cerdos-y-laspersonas.html 